\title{
Existence Theory for Pseudo-Symmetric Solution to $p$-Laplacian Differential Equations Involving Derivative
}

\author{
You-Hui Su, ${ }^{1}$ Weili $W{ }^{1}{ }^{1}$ and Xingjie Yan $^{2}$ \\ ${ }^{1}$ School of Mathematics and Physics, XuZhou Institute of Technology, Xuzhou, Jiangsu 221008, China \\ ${ }^{2}$ College of Sciences, China University of Mining and Technology, Xuzhou, Jiangsu 221008, China
}

Correspondence should be addressed to Xingjie Yan, yanxj04@cumt.edu.cn

Received 19 November 2010; Accepted 2 May 2011

Academic Editor: Yuri V. Rogovchenko

Copyright $(0) 2011$ You-Hui Su et al. This is an open access article distributed under the Creative Commons Attribution License, which permits unrestricted use, distribution, and reproduction in any medium, provided the original work is properly cited.

We all-sidedly consider a three-point boundary value problem for $p$-Laplacian differential equation with nonlinear term involving derivative. Some new sufficient conditions are obtained for the existence of at least one, triple, or arbitrary odd positive pseudosymmetric solutions by using pseudosymmetric technique and fixed-point theory in cone. As an application, two examples are given to illustrate the main results.

\section{Introduction}

Recent research results indicate that considerable achievement was made in the existence of positive solutions to dynamic equations; for details, please see [1-6] and the references therein. In particular, the existence of positive pseudosymmetric solutions to $p$-Laplacian difference and differential equations attract many researchers' attention, such as [7-11]. The reason is that the pseudosymmetry problem not only has theoretical value, such as in the study of metric manifolds [12], but also has practical value itself; for example, we can apply this characteristic into studying the chemistry structure [13]. On another hand, there are much attention paid to the positive solutions of boundary value problems (BVPs) for differential equation with the nonlinear term involved with the derivative explicitly [14-18]. Hence, it is natural to continue study pseudosymmetric solutions to $p$-Laplacian differential equations with the nonlinear term involved with the first-order derivative explicitly.

First, let us recall some relevant results about BVPs with $p$-Laplacian, We would like to mention the results of Avery and Henderson [7, 8], Ma and Ge [11] and Sun and Ge [16]. 
Throughout this paper, we denote the $p$-Laplacian operator by $\varphi_{p}(u)$; that is, $\varphi_{p}(u)=|u|^{p-2} u$ for $p>1$ with $\left(\varphi_{p}\right)^{-1}=\varphi_{q}$ and $1 / p+1 / q=1$.

For the three-point BVPs with $p$-Laplacian

$$
\begin{aligned}
\left(\varphi_{p}\left(u^{\prime}(t)\right)\right)^{\prime}+h(t) f(t, u(t)) & =0 \quad \text { for } t \in[0,1] \\
u(0)=0, \quad u(\eta) & =u(1)
\end{aligned}
$$

here, $\eta \in(0,1)$ is constant, by using the five functionals fixed point theorem in a cone [19], Avery and Henderson [8] established the existence of at least three positive pseudosymmetric solutions to BVPs (1.1). The authors also obtained the similar results in their paper [7] for the discrete case. In addition, Ma and Ge [11] developed the existence of at least two positive pseudosymmetric solutions to BVPs (1.1) by using the monotone iterative technique.

For the three-point $p$-Laplacian BVPs with dependence on the first-order derivative

$$
\begin{gathered}
\left(\varphi_{p}\left(u^{\prime}(t)\right)\right)^{\prime}+h(t) f\left(t, u(t), u^{\prime}(t)\right)=0 \quad \text { for } t \in[0,1] \\
u(0)=0, \quad u(\eta)=u(1),
\end{gathered}
$$

Sun and Ge [16] obtained the existence of at least two positive pseudosymmetric solutions to BVPs (1.2) via the monotone iterative technique again. However, it is worth mentioning that the above-mentioned papers $[7,8,10,11,16]$, the authors only considered results on the existence of positive pseudosymmetric solutions partly, they failed to further provide comprehensive results on the existence of positive pseudosymmetric solutions to $p$-Laplacian. Naturally, in this paper, we consider the existence of positive pseudosymmetric solutions for $p$-Laplacian differential equations in all respects.

Motivated by the references $[7,8,10,11,16,18]$, in present paper, we consider allsidedly $p$-Laplacian BVPs (1.2), using the compression and expansion fixed point theorem [20] and Avery-Peterson fixed point theorem [21]. We obtain that there exist at least one, triple or arbitrary odd positive pseudosymmetric solutions to problem (1.2). In particular, we not only get some local properties of pseudosymmetric solutions, but also obtain that the position of pseudosymmetric solutions is determined under some conditions, which is much better than the results in papers $[8,11,16]$. Correspondingly, we generalize and improve the results in papers Avery and Henderson [8]. From the view of applications, two examples are given to illustrate the main results.

Throughout this paper, we assume that

(S1) $f\left(t, u, u^{\prime}\right):[0,1] \times[0, \infty) \times(-\infty,+\infty) \rightarrow[0, \infty)$ is continuous, does not vanish identically on interval $[0,1]$, and $f\left(t, u, u^{\prime}\right)$ is pseudosymmetric about $\eta$ on $[0,1]$,

(S2) $h(t) \in L([0,1],[0, \infty))$ is pseudosymmetric about $\eta$ on $[0,1]$, and does not vanish identically on any closed subinterval of $[0,1]$. Furthermore, $0<\int_{0}^{1} h(t) d t<\infty$.

\section{Preliminaries}

In the preceding of this section, we state the definition of cone and several fixed point theorems needed later $[20,22]$. In the rest of this section, we will prove that solving BVPs (1.2) is equivalent to finding the fixed points of a completely continuous operator. 
We first list the definition of cone and the compression and expansion fixed point theorem $[20,22]$.

Definition 2.1. Let $E$ be a real Banach space. A nonempty, closed, convex set $P \subset E$ is said to be a cone provided the following conditions are satisfied:

(i) if $x \in P$ and $\lambda \geq 0$, then $\lambda x \in P$,

(ii) if $x \in P$ and $-x \in P$, then $x=0$.

Lemma 2.2 (see [20,22]). Let $P$ be a cone in a Banach space E. Assume that $\Omega_{1}, \Omega_{2}$ are open bounded subsets of $E$ with $0 \in \Omega_{1}, \bar{\Omega}_{1} \subset \Omega_{2}$. If $A: P \cap\left(\bar{\Omega}_{2} \backslash \Omega_{1}\right) \rightarrow P$ is a completely continuous operator such that either

(i) $\|A x\| \leq\|x\|, \forall x \in P \cap \partial \Omega_{1}$ and $\|A x\| \geq\|x\|, \forall x \in P \cap \partial \Omega_{2}$, or

(ii) $\|A x\| \geq\|x\|, \forall x \in P \cap \partial \Omega_{1}$ and $\|A x\| \leq\|x\|, \forall x \in P \cap \partial \Omega_{2}$.

Then, $A$ has a fixed point in $P \cap\left(\overline{\Omega_{2}} \backslash \Omega_{1}\right)$.

Given a nonnegative continuous functional $\gamma$ on a cone $P$ of a real Banach space $E$, we define, for each $d>0$, the set $P(\gamma, d)=\{x \in P: \gamma(x)<d\}$.

Let $\gamma$ and $\theta$ be nonnegative continuous convex functionals on $P, \alpha$ a nonnegative continuous concave functional on $P$, and $\psi$ a nonnegative continuous functional on $P$ respectively. We define the following convex sets:

$$
\begin{gathered}
P(\gamma, \alpha, b, d)=\{x \in P: b \leq \alpha(x), \gamma(x) \leq d\}, \\
P(\gamma, \theta, \alpha, b, c, d)=\{x \in P: b \leq \alpha(x), \theta(x) \leq c, \gamma(x) \leq d\},
\end{gathered}
$$

and a closed set $R(\gamma, \psi, a, d)=\{x \in P: a \leq \psi(x), \gamma(x) \leq d\}$.

Next, we list the fixed point theorem due to Avery-Peterson [21].

Lemma 2.3 (see [21]). Let $P$ be a cone in a real Banach space $E$ and $\gamma, \theta, \alpha, \psi$ defined as above; moreover, $\psi$ satisfies $\psi\left(\lambda^{\prime} x\right) \leq \lambda^{\prime} \psi(x)$ for $0 \leq \lambda^{\prime} \leq 1$ such that for some positive numbers $h$ and $d$,

$$
\alpha(x) \leq \psi(x),\|x\| \leq h \gamma(x),
$$

for all $x \in \overline{P(\gamma, d)}$. Suppose that $A: \overline{P(\gamma, d)} \rightarrow \overline{P(\gamma, d)}$ is completely continuous and there exist positive real numbers $a, b, c$ with $a<b$ such that

(i) $\{x \in P(\gamma, \theta, \alpha, b, c, d): \alpha(x)>b\} \neq \emptyset$ and $\alpha(A(x))>b$ for $x \in P(\gamma, \theta, \alpha, b, c, d)$,

(ii) $\alpha(A(x))>b$ for $x \in P(\gamma, \alpha, b, d)$ with $\theta(A(x))>c$,

(iii) $0 \notin R(\gamma, \psi, a, d)$ and $\psi(A(x))<$ a for all $x \in R(\gamma, \psi, a, d)$ with $\psi(x)=a$.

Then, $A$ has at least three fixed points $x_{1}, x_{2}, x_{3} \in \overline{P(\gamma, d)}$ such that

$$
\gamma\left(x_{i}\right) \leq d \text { for } i=1,2,3, b<\alpha\left(x_{1}\right), a<\psi\left(x_{2}\right), \alpha\left(x_{2}\right)<b \text { with } \psi\left(x_{3}\right)<a \text {. }
$$


Now, let $E=C^{1}([0,1], \mathbb{R})$. Then, $E$ is a Banach space with norm

$$
\|u\|=\max \left\{\max _{t \in[0,1]}|u(t)|, \max _{t \in[0,1]}\left|u^{\prime}(t)\right|\right\}
$$

Define a cone $P \subset E$ by

$P=\{u \in E \mid u(0)=0, u$ is concave, nonnegative on $[0,1]$ and $u$ is symmetricon $[\eta, 1]\}$

The following lemma can be founded in [11], which is necessary to prove our result.

Lemma 2.4 (see [11]). If $u \in P$, then the following statements are true:

(i) $u(t) \geq\left(u\left(\omega_{1}\right) / \omega_{1}\right) \min \{t, 1+\eta-t\}$ for $t \in[0,1]$, here $\omega_{1}=(\eta+1) / 2$,

(ii) $u(t) \geq\left(\eta / \omega_{1}\right) u\left(\omega_{1}\right)$ for $t \in\left[\eta, \omega_{1}\right]$,

(iii) $\max _{t \in[0,1]} u(t)=u\left(\omega_{1}\right)$.

Lemma 2.5. If $u \in P$, then the following statements are true:

(i) $u(t) \leq \max _{t \in[0,1]}\left|u^{\prime}(t)\right|$,

(ii) $\|u(t)\|=\max _{t \in[0,1]}\left|u^{\prime}(t)\right|=\max \left\{\left|u^{\prime}(0)\right|,\left|u^{\prime}(1)\right|\right\}$,

(iii) $\min _{t \in\left[0, \omega_{1}\right]} u(t)=u(0)$ and $\min _{t \in\left[\omega_{1}, 1\right]} u(t)=u(1)$.

Proof. (i) Since

$$
u(t)=u(0)+\int_{0}^{t} u^{\prime}(t) d t \quad \text { for } t \in[0,1]
$$

which reduces to

$$
u(t) \leq \int_{0}^{t}\left|u^{\prime}(t)\right| d t \leq \max _{t \in[0,1]}\left|u^{\prime}(t)\right|
$$

(ii) By using $u^{\prime \prime}(t) \leq 0$ for $t \in[0,1]$, we have $u^{\prime}(t)$ is monotone decreasing function on $[0,1]$. Moreover,

$$
\max _{t \in[0,1]} u(t)=u\left(\frac{\eta+1}{2}\right)=u\left(\omega_{1}\right)
$$

which implies that $u^{\prime}\left(\omega_{1}\right)=0$, so, $u^{\prime}(t) \geq 0$ for $t \in\left[0, \omega_{1}\right]$ and $u^{\prime}(t) \leq 0$ for $t \in\left[\omega_{1}, 1\right]$. 
Now, we define the operator $A: P \rightarrow E$ by

$$
(A u)(t)=\left\{\begin{array}{l}
\int_{0}^{t} \varphi_{q}\left(\int_{s}^{\omega_{1}} h(r) f\left(r, u(r), u^{\prime}(r)\right) d r\right) d s \quad \text { for } t \in\left[0, \omega_{1}\right] \\
w(\eta)+\int_{t}^{1} \varphi_{q}\left(\int_{\omega_{1}}^{s} h(r) f\left(r, u(r), u^{\prime}(r)\right) d r\right) d s \quad \text { for } t \in\left[\omega_{1}, 1\right]
\end{array}\right.
$$

here, $w(\eta)=(A u)(\eta)$.

Lemma 2.6. $A: P \rightarrow P$ is a completely continuous operator.

Proof. In fact, $(A u)(t) \geq 0$ for $t \in[0,1],(A u)(\eta)=(A u)(1)$ and $(A u)(0)=0$.

It is easy to see that the operator $A$ is pseudosymmetric about $\omega_{1}$ on $[0,1]$.

In fact, for $t \in\left[\eta, \omega_{1}\right]$, we have $1-t+\eta \in\left[\omega_{1}, 1\right]$, and according to the integral transform, one has

$$
\begin{aligned}
& \int_{1-t+\eta}^{1} \varphi_{q}\left(\int_{\omega_{1}}^{s} h(r) f\left(r, u(r), u^{\prime}(r)\right) d r\right) d s \\
& =\int_{\eta}^{t} \varphi_{q}\left(\int_{s_{1}}^{\omega_{1}} h\left(r_{1}\right) f\left(r_{1}, u\left(r_{1}\right), u^{\prime}\left(r_{1}\right)\right) d r_{1}\right) d s_{1}
\end{aligned}
$$

here, $s=1-s_{1}+\eta, r=1-r_{1}+\eta$. Hence,

$$
\begin{aligned}
(A u)(1-t+\eta)= & w(\eta)+\int_{1-t+\eta}^{1} \varphi_{q}\left(\int_{\omega_{1}}^{s} h(r) f\left(r, u(r), u^{\prime}(r)\right) d r\right) d s \\
= & w(\eta)+\int_{\eta}^{t} \varphi_{q}\left(\int_{s_{1}}^{\omega_{1}} h\left(r_{1}\right) f\left(r_{1}, u\left(r_{1}\right), u^{\prime}\left(r_{1}\right)\right) d r_{1}\right) d s_{1} \\
= & \int_{0}^{\eta} \varphi_{q}\left(\int_{s}^{\omega_{1}} h(r) f\left(r, u(r), u^{\prime}(r)\right) d r\right) d s \\
& +\int_{\eta}^{t} \varphi_{q}\left(\int_{s}^{\omega_{1}} h(r) f\left(r, u(r), u^{\prime}(r)\right) d r\right) d s \\
= & \int_{0}^{t} \varphi_{q}\left(\int_{s}^{\omega_{1}} h(r) f\left(r, u(r), u^{\prime}(r)\right) d r\right) d s=(A u)(t) .
\end{aligned}
$$

For $t \in\left[\omega_{1}, 1\right]$, we note that $1-t+\eta \in\left[\eta, \omega_{1}\right]$, by using the integral transform, one has

$$
\begin{aligned}
\int_{\eta}^{1-t+\eta} & \varphi_{q}\left(\int_{s}^{\omega_{1}} h(r) f\left(r, u(r), u^{\prime}(r)\right) d r\right) d s \\
= & \int_{t}^{1} \varphi_{q}\left(\int_{\omega_{1}}^{s_{1}} h\left(r_{1}\right) f\left(r_{1}, u\left(r_{1}\right), u^{\prime}\left(r_{1}\right)\right) d r_{1}\right) d s_{1}
\end{aligned}
$$


where $s=1-s_{1}+\eta, r=1-r_{1}+\eta$. Thus,

$$
\begin{aligned}
(A u)(1-t+\eta) & =\int_{0}^{1-t+\eta} \varphi_{q}\left(\int_{s}^{\omega_{1}} h(r) f\left(r, u(r), u^{\prime}(r)\right) d r\right) d s \\
& =w(\eta)+\int_{\eta}^{1-t+\eta} \varphi_{q}\left(\int_{s}^{\omega_{1}} h(r) f\left(r, u(r), u^{\prime}(r)\right) d r\right) d s \\
& =w(\eta)+\int_{t}^{1} \varphi_{q}\left(\int_{\omega_{1}}^{s_{1}} h\left(r_{1}\right) f\left(r_{1}, u\left(r_{1}\right), u^{\prime}\left(r_{1}\right)\right) d r_{1}\right) d s_{1} \\
& =w(\eta)+\int_{t}^{1} \varphi_{q}\left(\int_{\omega_{1}}^{s} h(r) f\left(r, u(r), u^{\prime}(r)\right) d r\right) d s=(A u)(t) .
\end{aligned}
$$

Hence, $A$ is pseudosymmetric about $\eta$ on $[0,1]$.

In addition,

$$
(A u)^{\prime}(t)=\varphi_{q}\left(\int_{t}^{\omega_{1}} h(r) f\left(r, u(r), u^{\prime}(r)\right) d s\right) \geq 0, t \in\left[0, \omega_{1}\right]
$$

is continuous and nonincreasing in $\left[0, \omega_{1}\right]$; moreover, $\varphi_{q}(x)$ is a monotone increasing continuously differentiable function

$$
\left(\int_{t}^{\omega_{1}} h(s) f\left(s, u(s), u^{\prime}(s)\right) d s\right)^{\prime}=-h(t) f\left(t, u(t), u^{\prime}(t)\right) \leq 0, t \in\left[0, \omega_{1}\right]
$$

it is easy to obtain $(A u)^{\prime \prime}(t) \leq 0$ for $t \in\left[0, \omega_{1}\right]$. By using the similar way, we can deduce $(A u)^{\prime \prime}(t) \leq 0$ for $t \in\left[\omega_{1}, 1\right]$. So, $A: P \rightarrow P$. It is easy to obtain that $A: P \rightarrow P$ is completely continuous.

Hence, the solutions of BVPs (1.2) are fixed points of the completely continuous operator $A$.

\section{One Solutions}

In this section, we will study the existence of one positive pseudosymmetric solution to problem (1.2) by Krasnosel'skii's fixed point theorem in a cone. 
Motivated by the notations in reference [23], for $u \in P$, let

$$
\begin{aligned}
f^{0} & =\sup _{t \in[0,1]} \lim _{\left(u, u^{\prime}\right) \rightarrow(0,0)} \frac{f\left(t, u, u^{\prime}\right)}{\varphi_{p}\left(\left|u^{\prime}\right|\right)}, \\
f_{0} & =\inf _{t \in[0,1]\left(u, u^{\prime}\right) \rightarrow(0,0)} \lim _{f^{\infty}}=\sup _{t \in[0,1]} \lim _{\varphi_{p}\left(\mid u^{\prime}\right) \rightarrow\left(\infty, u, u^{\prime}\right)} \frac{f\left(t, u, u^{\prime}\right)}{\varphi_{p}\left(\left|u^{\prime}\right|\right)}, \\
f_{\infty} & =\inf _{t \in[0,1]\left(u, u^{\prime}\right) \rightarrow(\infty, \infty)} \lim _{\frac{f\left(t, u, u^{\prime}\right)}{\varphi_{p}\left(\left|u^{\prime}\right|\right)} .}
\end{aligned}
$$

In the following, we discuss the problem (1.2) under the following four possible cases.

Theorem 3.1. If $f^{0}=0$ and $f_{\infty}=\infty$, problem (1.2) has at least one positive pseudosymmetric solution $u$.

Proof. In view of $f^{0}=0$, there exists an $H_{1}>0$ such that

$$
f\left(t, u, u^{\prime}\right) \leq \varphi_{p}(\varepsilon) \varphi_{p}\left(\left|u^{\prime}\right|\right)=\varphi_{p}\left(\varepsilon\left|u^{\prime}\right|\right) \quad \text { for }\left(t, u, u^{\prime}\right) \in[0,1] \times\left(0, H_{1}\right] \times\left[-H_{1}, H_{1}\right],
$$

here, $\varepsilon>0$ and satisfies

$$
\varepsilon \varphi_{q}\left(\int_{0}^{\omega_{1}} h(s) d s\right) \leq 1
$$

If $u \in P$ with $\|u\|=H_{1}$, by Lemma 2.5 , we have

$$
u(t) \leq \max _{t \in[0,1]}\left|u^{\prime}(t)\right| \leq\|u\|=H_{1} \quad \text { for } t \in[0,1]
$$

hence,

$$
\begin{aligned}
\|A u\| & =\max \left\{\left|(A u)^{\prime}(0)\right|,\left|(A u)^{\prime}(1)\right|\right\} \\
& =\max \left\{\varphi_{q}\left(\int_{0}^{\omega_{1}} h(r) f\left(r, u(r), u^{\prime}(r)\right) d r\right), \varphi_{q}\left(\int_{\omega_{1}}^{1} h(r) f\left(r, u(r), u^{\prime}(r)\right) d r\right)\right\} \\
& \leq \varepsilon \max _{t \in[0,1]}\left|u^{\prime}(t)\right| \varphi_{q}\left(\int_{0}^{\omega_{1}} h(s) d s\right) \leq\|u\| .
\end{aligned}
$$

If set $\Omega_{H_{1}}=\left\{u \in E:\|u\|<H_{1}\right\}$, one has $\|A u\| \leq\|u\|$ for $u \in P \cap \partial \Omega_{H_{1}}$.

According to $f_{\infty}=\infty$, there exists an $H_{2}^{\prime}>0$ such that

$$
f\left(t, u, u^{\prime}\right) \geq \max _{t \in[0,1]} \varphi_{p}(k) \varphi_{p}\left(\left|u^{\prime}\right|\right)=\max _{t \in[0,1]} \varphi_{p}\left(k\left|u^{\prime}\right|\right),
$$


where $\left(t, u, u^{\prime}\right) \in[0,1] \times\left[H_{2}^{\prime}, \infty\right) \times\left(-\infty, H_{2}^{\prime}\right] \cup\left[H_{2}^{\prime}, \infty\right), k>0$ and satisfies

$$
k \varphi_{q}\left(\int_{\omega_{1}}^{1} h(r) d r\right) \geq 1
$$

Set

$$
\begin{gathered}
H_{2}=\max \left\{2 H_{1}, \frac{\omega_{1}}{\eta} H_{2}^{\prime}\right\}, \Omega_{H_{2}^{*}}=\left\{u \in E:\|u\|<5 H_{2}\right\}, \\
\Omega_{H_{2}}=\left\{u \in \Omega_{H_{2}^{*}}: u\left(\omega_{1}\right)<H_{2}\right\} .
\end{gathered}
$$

For $u \in P \cap \partial \Omega_{H_{2}}$, we have $u\left(\omega_{1}\right)=H_{2}$ since $u(t) \leq\left|u^{\prime}(t)\right|$ for $u \in P$.

If $u \in P$ with $u\left(\omega_{1}\right)=H_{2}$, Lemmas 2.4 and 2.5 reduce to

$$
\min _{t \in\left[\omega_{1}, 1\right]}\left|u^{\prime}(t)\right| \geq \min _{t \in\left[\omega_{1}, 1\right]} u(t)=u(1) \geq \frac{\eta u\left(\omega_{1}\right)}{\omega_{1}} \geq H_{2}^{\prime}
$$

For $u \in P \cap \partial \Omega_{H_{2}}$, according to (3.6), (3.7) and (3.9), we get

$$
\begin{aligned}
\|A u\| & =\max \left\{\varphi_{q}\left(\int_{0}^{\omega_{1}} h(r) f\left(r, u(r), u^{\prime}(r)\right) d r\right), \varphi_{q}\left(\int_{\omega_{1}}^{1} h(r) f\left(r, u(r), u^{\prime}(r)\right) d r\right)\right\} \\
& \geq \varphi_{q}\left(\int_{\omega_{1}}^{1} h(r) f\left(r, u(r), u^{\prime}(r)\right) d r\right) \\
& \geq k \max _{t \in[0,1]}\left|u^{\prime}(t)\right| \varphi_{q}\left(\int_{1}^{\omega_{1}} h(r) d r\right)=\|u\| .
\end{aligned}
$$

Thus, by (i) of Lemma 2.2, the problem (1.2) has at least one positive pseudosymmetric solution $u$ in $P \cap\left(\bar{\Omega}_{H_{2}} \backslash \Omega_{H_{1}}\right)$.

Theorem 3.2. If $f_{0}=\infty$ and $f^{\infty}=0$, problem (1.2) has at least one positive pseudosymmetric solution $u$.

Proof. Since $f_{0}=\infty$, there exists an $H_{3}>0$ such that

$$
f\left(t, u, u^{\prime}\right) \geq \max _{t \in[0,1]} \varphi_{p}(m) \varphi_{p}\left(\left|u^{\prime}\right|\right)=\max _{t \in[0,1]} \varphi_{p}\left(m\left|u^{\prime}\right|\right),
$$

here, $\left(t, u, u^{\prime}\right) \in[0,1] \times\left(0, H_{3}\right] \times\left[-H_{3}, H_{3}\right]$ and $m$ is such that

$$
m \varphi_{q}\left(\int_{\omega_{1}}^{1} h(r) d r\right) \geq 1
$$


If $u \in P$ with $\|u\|=H_{3}$, Lemma 2.5 implies that

$$
u(t) \leq \max _{t \in[0,1]}\left|u^{\prime}(t)\right| \leq\|u\|=H_{3} \quad \text { for } t \in[0,1],
$$

now, by (3.11), (3.12), and (3.13), we have

$$
\begin{aligned}
\|A u\| & =\max \left\{\varphi_{q}\left(\int_{0}^{\omega_{1}} h(r) f\left(r, u(r), u^{\prime}(r)\right) d r\right), \varphi_{q}\left(\int_{\omega_{1}}^{1} h(r) f\left(r, u(r), u^{\prime}(r)\right) d r\right)\right\} \\
& \geq \varphi_{q}\left(\int_{\omega_{1}}^{1} h(r) f\left(r, u(r), u^{\prime}(r)\right) d r\right) \geq m \max _{t \in[0,1]}\left|u^{\prime}(t)\right| \varphi_{q}\left(\int_{\omega_{1}}^{1} h(r) d r\right)=\|u\| .
\end{aligned}
$$

If let $\Omega_{H_{3}}=\left\{u \in E:\|u\|<H_{3}\right\}$, one has $\|A u\| \geq\|u\|$ for $u \in P \cap \partial \Omega_{H_{3}}$.

Now, we consider $f^{\infty}=0$.

Suppose that $f$ is bounded, for some constant $K>0$, then

$$
f\left(t, u, u^{\prime}\right) \leq \varphi_{p}(K) \quad \forall\left(t, u, u^{\prime}\right) \in[0,1] \times[0, \infty) \times(-\infty, \infty) .
$$

Pick

$$
H_{4} \geq \max \left\{H_{4}^{\prime}, 2 H_{3}, K \varphi_{q}\left(\int_{0}^{\omega_{1}} h(s) d s\right), \frac{C}{\delta}\right\}
$$

here, $C$ is an arbitrary positive constant and satisfy the (3.21). Let

$$
\Omega_{H_{4}}=\left\{u \in E:\|u\|<H_{4}\right\} .
$$

If $u \in P \cap \partial \Omega_{H_{4}}$, one has $\|u\|=H_{4}$, then (3.15) and (3.16) imply that

$$
\begin{aligned}
\|A u\| & =\max \left\{\varphi_{q}\left(\int_{0}^{\omega_{1}} h(r) f\left(r, u(r), u^{\prime}(r)\right) d r\right), \varphi_{q}\left(\int_{\omega_{1}}^{1} h(r) f\left(r, u(r), u^{\prime}(r)\right) d r\right)\right\} \\
& \leq K \varphi_{q}\left(\int_{0}^{\omega_{1}} h(s) d s\right) \leq H_{4}=\|u\| .
\end{aligned}
$$

Suppose that $f$ is unbounded.

By definition of $f^{\infty}=0$, there exists $H_{4}^{\prime}>0$ such that

$$
f\left(t, u, u^{\prime}\right) \leq \varphi_{p}(\delta) \varphi_{p}\left(\left|u^{\prime}\right|\right)=\varphi_{p}\left(\delta\left|u^{\prime}\right|\right)
$$

where $\left(t, u, u^{\prime}\right) \in\left[0, \omega_{1}\right] \times\left[H_{4}^{\prime}, \infty\right) \times\left(-\infty, H_{4}^{\prime}\right] \cup\left[H_{4}^{\prime}, \infty\right)$ and $\delta>0$ satisfies

$$
\delta \varphi_{q}\left(\int_{0}^{\omega_{1}} h(s) d s\right) \leq 1 .
$$


From $f \in C([0,1] \times[0,+\infty) \times(-\infty, \infty),[0,+\infty))$, we have

$$
f\left(t, u, u^{\prime}\right) \leq \varphi_{p}(C) \quad \text { for }\left(t, u, u^{\prime}\right) \in[0,1] \times\left[0, H_{4}^{\prime}\right] \times\left[-H_{4}^{\prime}, H_{4}^{\prime}\right]
$$

here, $C$ is an arbitrary positive constant.

Then, for $\left(t, u, u^{\prime}\right) \in[0,1] \times[0, \infty) \times(-\infty, \infty)$, we have

$$
f\left(t, u, u^{\prime}\right) \leq \max \left\{\varphi_{p}(C), \varphi_{p}(\delta) \varphi_{p}\left(\left|u^{\prime}\right|\right)\right\}
$$

If $u \in P \cap \partial \Omega_{H_{4}}$, one has $\|u\|=H_{4}$, which reduces to

$$
\begin{aligned}
\|A u\| & =\max \left\{\varphi_{q}\left(\int_{0}^{\omega_{1}} h(r) f\left(r, u(r), u^{\prime}(r)\right) d r\right), \varphi_{q}\left(\int_{\omega_{1}}^{1} h(r) f\left(r, u(r), u^{\prime}(r)\right) d r\right)\right\} \\
& \leq \max \left\{C, \delta\left\|u^{\prime}\right\|\right\} \varphi_{q}\left(\int_{0}^{\omega_{1}} h(r) d r\right) \\
& \leq H_{4}=\|u\| .
\end{aligned}
$$

Consequently, for any cases, if we take $\Omega_{H_{4}}=\left\{u \in E:\|u\|<H_{4}\right\}$, we have $\|A u\| \leq\|u\|$ for $u \in$ $P \cap \partial \Omega_{H_{4}}$. Thus, the condition (ii) of Lemma 2.2 is satisfied.

Consequently, the problem (1.2) has at least one positive pseudosymmetric solution

$$
u \in P \cap\left(\bar{\Omega}_{H_{4}} \backslash \Omega_{H_{3}}\right) \text { with } H_{3} \leq\|u\| \leq H_{4}
$$

Theorem 3.3. Suppose that the following conditions hold:

(i) there exist nonzero finite constants $c_{1}$ and $c_{2}$ such that $f^{0}=c_{1}$ and $f_{\infty}=c_{2}$,

(ii) there exist nonzero finite constants $c_{3}$ and $c_{4}$ such that $f_{0}=c_{3}$ and $f^{\infty}=c_{4}$.

Then, problem (1.2) has at least one positive pseudosymmetric solution $u$.

Proof. (i) In view of $f^{0}=c_{1}$, there exists an $H_{5}>0$ such that

$$
\begin{aligned}
f\left(t, u, u^{\prime}\right) & \leq \varphi_{p}\left(\varepsilon+c_{11}\right) \varphi_{p}\left(\left|u^{\prime}\right|\right) \\
& =\varphi_{p}\left(\left(\varepsilon+c_{11}\right)\left|u^{\prime}\right|\right) \quad \text { for }\left(t, u, u^{\prime}\right) \in[0,1] \times\left(0, H_{5}\right] \times\left[-H_{5}, H_{5}\right]
\end{aligned}
$$

here, $c_{1}=\varphi_{p}\left(c_{11}+\varepsilon\right), \varepsilon>0$ and satisfies

$$
\left(\varepsilon+c_{11}\right) \varphi_{q}\left(\int_{0}^{\omega_{1}} h(s) d s\right) \leq 1 .
$$

If $u \in P$ with $\|u\|=H_{5}$, by Lemma 2.5, we have

$$
u(t) \leq\left|u^{\prime}(t)\right| \leq\|u\|=H_{5} \quad \text { for } t \in[0,1]
$$


hence,

$$
\begin{aligned}
\|A u\| & =\max \left\{\left|(A u)^{\prime}(0)\right|,\left|(A u)^{\prime}(1)\right|\right\} \\
& =\max \left\{\varphi_{q}\left(\int_{0}^{\omega_{1}} h(r) f\left(r, u(r), u^{\prime}(r)\right) d r\right), \varphi_{q}\left(\int_{\omega_{1}}^{1} h(r) f\left(r, u(r), u^{\prime}(r)\right) d r\right)\right\} \\
& \leq\left(\varepsilon+c_{11}\right) \max _{t \in[0,1]}\left|u^{\prime}(t)\right| \varphi_{q}\left(\int_{0}^{\omega_{1}} h(s) d s\right) \leq\|u\| .
\end{aligned}
$$

If set $\Omega_{H_{5}}=\left\{u \in E:\|u\|<H_{5}\right\}$, one has $\|A u\| \leq\|u\|$ for $u \in P \cap \partial \Omega_{H_{5}}$.

According to $f_{\infty}=c_{2}$, there exists an $H_{6}^{\prime}>0$ such that

$$
f\left(t, u, u^{\prime}\right) \geq \max _{t \in[0,1]} \varphi_{p}\left(c_{22}-\varepsilon\right) \varphi_{p}\left(\left|u^{\prime}\right|\right)=\max _{t \in[0,1]} \varphi_{p}\left(\left(c_{22}-\varepsilon\right)\left|u^{\prime}\right|\right),
$$

where $\left(t, u, u^{\prime}\right) \in[0,1] \times\left[H_{6}^{\prime}, \infty\right) \times\left(-\infty, H_{6}^{\prime}\right] \cup\left[H_{6}^{\prime}, \infty\right), c_{2}=\varphi_{p}\left(c_{22}-\varepsilon\right), \varepsilon>0$ and satisfies

$$
\left(c_{22}-\varepsilon\right) \varphi_{q}\left(\int_{\omega_{1}}^{1} h(r) d r\right) \geq 1 .
$$

Set

$$
\begin{gathered}
H_{6}=\max \left\{2 H_{5}, \frac{\omega_{1}}{\eta} H_{6}^{\prime}\right\}, \quad \Omega_{H_{6}^{*}}=\left\{u \in E:\|u\|<5 H_{6}\right\}, \\
\Omega_{H_{6}}=\left\{u \in \Omega_{H_{6}^{*}}: u\left(\omega_{1}\right)<H_{6}\right\} .
\end{gathered}
$$

If $u \in P$ with $u\left(\omega_{1}\right)=H_{6}$, Lemmas 2.4 and 2.5 reduce to

$$
\min _{t \in\left[\omega_{1}, 1\right]}\left|u^{\prime}(t)\right| \geq \min _{t \in\left[\omega_{1}, 1\right]} u(t)=u(1) \geq \frac{\eta u\left(\omega_{1}\right)}{\omega_{1}} \geq H_{6}^{\prime}
$$

For $u \in P \cap \partial \Omega_{H_{6}}$, according to (3.29), (3.30) and (3.32), we get

$$
\begin{aligned}
\|A u\| & =\max \left\{\varphi_{q}\left(\int_{0}^{\omega_{1}} h(r) f\left(r, u(r), u^{\prime}(r)\right) d r\right), \varphi_{q}\left(\int_{\omega_{1}}^{1} h(r) f\left(r, u(r), u^{\prime}(r)\right) d r\right)\right\} \\
& \geq \varphi_{q}\left(\int_{\omega_{1}}^{1} h(r) f\left(r, u(r), u^{\prime}(r)\right) d r\right) \\
& \geq\left(c_{22}-\varepsilon\right) \max _{t \in[0,1]}\left|u^{\prime}(t)\right| \varphi_{q}\left(\int_{1}^{\omega_{1}} h(r) d r\right)=\|u\| .
\end{aligned}
$$

Thus, by (i) of Lemma 2.2, the problem (1.2) has at least one positive pseudosymmetric solution $u$ in $P \cap\left(\bar{\Omega}_{H_{6}} \backslash \Omega_{H_{5}}\right)$.

(ii) By using the similar way as to Theorem 3.2, we can prove to it. 


\section{Triple Solutions}

In the previous section, some results on the existence of at least one positive pseudosymmetric solutions to problem (1.2) are obtained. In this section, we will further discuss the existence criteria for at least three and arbitrary odd positive pseudosymmetric solutions of problems (1.2) by using the Avery-Peterson fixed point theorem [21].

Choose a $r \in\left(\eta, \omega_{1}\right)$, for the notational convenience, we denote

$$
M=\omega_{1} \varphi_{q}\left(\int_{0}^{\omega_{1}} h(r) d r\right), \quad N=\eta \varphi_{q}\left(\int_{\eta}^{\omega_{1}} h(r) d r\right), \quad W=\varphi_{q}\left(\int_{0}^{\omega_{1}} h(r) d r\right) .
$$

Define the nonnegative continuous convex functionals $\theta$ and $\gamma$, nonnegative continuous concave functional $\alpha$, and nonnegative continuous functional $\varphi$, respectively, on $P$ by

$$
\begin{gathered}
r(u)=\max _{t \in[0,1]}\left|u^{\prime}(t)\right|=\max \left\{u^{\prime}(0), u^{\prime}(1)\right\}=\|u\|, \\
\psi(u)=\theta(u)=\max _{t \in\left[0, \omega_{1}\right]} u(t)=u\left(\omega_{1}\right) \leq\|u\|, \\
\alpha(u)=\min _{t \in\left[\eta, \omega_{1}\right]} u(t)=u(\eta) .
\end{gathered}
$$

Now, we state and prove the results in this section.

Theorem 4.1. Suppose that there exist constants $a^{*}, b^{*}$, and $d^{*}$ such that $0<a^{*}<b^{*}<(N / W) d^{*}$. In addition, $f$ satisfies the following conditions:

(i) $f\left(t, u, u^{\prime}\right) \leq \varphi_{p}\left(d^{*} / W\right)$ for $\left(t, u, u^{\prime}\right) \in[0,1] \times\left[0, d^{*}\right] \times\left[-d^{*}, d^{*}\right]$,

(ii) $f\left(t, u, u^{\prime}\right)>\varphi_{p}\left(b^{*} / N\right)$ for $\left(t, u, u^{\prime}\right) \in\left[\eta, \omega_{1}\right] \times\left[b^{*}, d^{*}\right] \times\left[-d^{*}, d^{*}\right]$,

(iii) $f\left(t, u, u^{\prime}\right)<\varphi_{p}\left(a^{*} / M\right)$ for $\left(t, u, u^{\prime}\right) \in\left[0, \omega_{1}\right] \times\left[0, a^{*}\right] \times\left[-d^{*}, d^{*}\right]$. that

Then, problem (1.2) has at least three positive pseudosymmetric solutions $u_{1}, u_{2}$, and $u_{3}$ such

$$
\begin{gathered}
\left\|x_{i}\right\| \leq d^{*} \quad \text { for } i=1,2,3, b^{*}<\min _{t \in\left[\eta, \omega_{1}\right]} u_{1}(t), a^{*}<\max _{t \in[0,1]} u_{2}(t), \\
\min _{t \in\left[\eta, \omega_{1}\right]} u_{2}(t)<b^{*} \quad \text { with } \max _{t \in[0,1]} u_{3}(t)<a^{*} .
\end{gathered}
$$

Proof. According to the definition of completely continuous operator $A$ and its properties, we need to show that all the conditions of Lemma 2.3 hold with respect to $A$.

It is obvious that

$$
\begin{gathered}
\psi\left(\lambda^{\prime} u\right)=\lambda^{\prime} u\left(\omega_{1}\right)=\lambda^{\prime} \psi(u) \quad \text { for } 0<\lambda^{\prime}<1, \\
\alpha(u) \leq \psi(u) \quad \forall u \in P, \\
\|u\|=\gamma(u) \quad \forall u \in P .
\end{gathered}
$$


Firstly, we show that $A: \overline{P\left(\gamma, d^{*}\right)} \rightarrow \overline{P\left(\gamma, d^{*}\right)}$.

For any $u \in \overline{P\left(\gamma, d^{*}\right)}$, we have

$$
u(t) \leq \max _{t \in[0,1]}\left|u^{\prime}(t)\right| \leq\|u\|=\gamma(u) \leq d^{*} \quad \text { for } t \in[0,1]
$$

hence, the assumption (i) implies that

$$
\begin{aligned}
\|A u\| & =\max \left\{\varphi_{q}\left(\int_{0}^{\omega_{1}} h(r) f\left(r, u(r), u^{\prime}(r)\right) d r\right), \varphi_{q}\left(\int_{\omega_{1}}^{1} h(r) f\left(r, u(r), u^{\prime}(r)\right) d r\right)\right\} \\
& \leq \frac{d^{*}}{W} \varphi_{q}\left(\int_{0}^{\omega_{1}} h(r) d r\right)=d^{*} .
\end{aligned}
$$

From the above analysis, it remains to show that (i)-(iii) of Lemma 2.3 hold.

Secondly, we verify that condition (i) of Lemma 2.3 holds; let $u(t) \equiv\left(t b^{*} / \eta\right)+b^{*}, t \in$ $[0,1]$, and it is easy to see that

$$
\begin{gathered}
\alpha(u)=u(\eta)=2 b^{*}>b^{*}, \\
\theta(u)=u\left(\omega_{1}\right)=\frac{\omega_{1} b^{*}}{\eta}+b^{*} \leq \frac{\omega_{1} b^{*}}{\eta}+b^{*},
\end{gathered}
$$

in addition, we have $\gamma(u)=\left(b^{*} / \eta\right)<d^{*}$, since $b^{*}<(N / W) d^{*}$. Thus

$$
\left\{u \in P\left(\gamma, \theta, \alpha, b^{*}, \frac{\omega_{1} b^{*}}{\eta}+b^{*}, d^{*}\right): \alpha(x)>b^{*}\right\} \neq \emptyset .
$$

For any

$$
u \in P\left(\gamma, \theta, \alpha, b^{*}, \frac{\omega_{1} b^{*}}{\eta}+b^{*}, d^{*}\right),
$$

one has

$$
b^{*} \leq u(t) \leq\|u\| \leq d^{*} \quad \forall t \in\left[\eta, \omega_{1}\right],
$$

it follows from the assumption (ii) that

$$
\begin{aligned}
\alpha(A u) & =(A u)(\eta)=\int_{0}^{\eta} \varphi_{q}\left(\int_{s}^{\omega_{1}} h(r) f\left(r, u(r), u^{\prime}(r)\right) d r\right) d s \\
& \geq \int_{0}^{\eta} \varphi_{q}\left(\int_{\eta}^{\omega_{1}} h(r) f\left(r, u(r), u^{\prime}(r)\right) d r\right) d s \\
& >\frac{b^{*}}{N} \eta \varphi_{q}\left(\int_{\eta}^{\omega_{1}} h(r) d r\right)=b^{*} .
\end{aligned}
$$


Thirdly, we prove that the condition (ii) of Lemma 2.3 holds. In fact,

$$
\begin{gathered}
\alpha(A u)=A u(\eta), \\
\theta(A u)=\max _{t \in\left[0, \omega_{1}\right]} A(u)=A u\left(\omega_{1}\right) .
\end{gathered}
$$

For any $u \in P\left(\gamma, \alpha, b^{*}, d^{*}\right)$ with $\theta(A u)>\left(\omega_{1} b^{*} / \eta\right)+b^{*}$, we have

$$
\alpha(A u)=A u(\eta) \geq \frac{\eta}{\omega_{1}} A u\left(\omega_{1}\right) \geq \frac{\eta}{\omega_{1}} \theta(A u)=b^{*}+\frac{\omega_{1} b^{*}}{\eta}>b^{*} .
$$

Finally, we check condition (iii) of Lemma 2.3.

Clearly, since $\psi(0)=0<a^{*}$, we have $0 \notin R\left(\gamma, \psi, a^{*}, d^{*}\right)$. If

$$
u \in R\left(\gamma, \psi, a^{*}, d^{*}\right) \text { with } \psi(u)=\max _{t \in\left[0, \omega_{1}\right]} u(t)=u\left(\omega_{1}\right)=a^{*},
$$

then

$$
\begin{gathered}
0 \leq u(t) \leq a^{*} \quad \forall t \in\left[0, \omega_{1}\right], \\
\max _{t \in[0,1]}\left|u^{\prime}(t)\right|=\|u\|=\gamma(u) \leq d^{*} .
\end{gathered}
$$

Hence, by assumption (iii), we have

$$
\begin{aligned}
\psi(A u) & =(A u)\left(\omega_{1}\right) \\
& \leq \int_{0}^{\omega_{1}} \varphi_{q}\left(\int_{0}^{\omega_{1}} h(r) f\left(r, u(r), u^{\prime}(r)\right) d r\right) d s \\
& <\frac{a^{*}}{M} \omega_{1} \varphi_{q}\left(\int_{0}^{\omega_{1}} h(r) d r\right)=a^{*} .
\end{aligned}
$$

Consequently, from above, all the conditions of Lemma 2.3 are satisfied. The proof is completed.

Corollary 4.2. If the condition (i) in Theorem 4.1 is replaced by the following condition ( $\left.i^{\prime}\right)$ :

(i') $\lim _{\left(u, u^{\prime}\right) \rightarrow(\infty, \infty)}\left(f\left(t, u, u^{\prime}\right) /\left(\varphi_{p}\left(\left|u^{\prime}\right|\right)\right)\right) \leq \varphi_{p}(1 / W)$,

then the conclusion of Theorem 4.1 also holds.

Proof. From Theorem 4.1, we only need to prove that (i') implies that (i) holds. That is, assume that ( $\left.\mathrm{i}^{\prime}\right)$ holds, then there exists a number $d^{*} \geq(W / N) b^{*}$ such that

$$
f\left(t, u, u^{\prime}\right) \leq \varphi_{p}\left(\frac{d^{*}}{W}\right) \quad \text { for }\left(t, u, u^{\prime}\right) \in[0,1] \times\left[0, d^{*}\right] \times\left[-d^{*}, d^{*}\right]
$$


Suppose on the contrary that for any $d^{*} \geq(W / N) b^{*}$, there exists $\left(u_{c}, u_{c}^{\prime}\right) \in\left[0, d^{*}\right] \times$ $\left[-d^{*}, d^{*}\right]$ such that

$$
f\left(t, u_{c}, u_{c}^{\prime}\right)>\varphi_{p}\left(\frac{d^{*}}{W}\right) \text { for } t \in[0,1]
$$

Hence, if we choose $c_{n}^{*}>(W / N) b^{*}(n=1,2, \ldots)$ with $c_{n}^{*} \rightarrow \infty$, then there exist $\left(u_{n}, u_{n}^{\prime}\right) \in$ $\left[0, c_{n}^{*}\right] \times\left[-c_{n}^{*}, c_{n}^{*}\right]$ such that

$$
f\left(t, u_{n}, u_{n}^{\prime}\right)>\varphi_{p}\left(\frac{c_{n}^{*}}{W}\right) \text { for } t \in[0,1]
$$

and so

$$
\lim _{n \rightarrow \infty} f\left(t, u_{n}, u_{n}^{\prime}\right)=\infty \quad \text { for } t \in[0,1]
$$

Since the condition ( $\left.\mathrm{i}^{\prime}\right)$ holds, there exists $\tau>0$ satisfying

$$
f\left(t, u, u^{\prime}\right) \leq \varphi_{p}\left(\frac{\left|u^{\prime}\right|}{W}\right) \quad \text { for }\left(t, u, u^{\prime}\right) \in[0,1] \times[\tau, \infty) \times(-\infty, \tau] \cup[\tau, \infty)
$$

Hence, we have

$$
u_{n}<\left|u_{n}^{\prime}\right| \leq \tau
$$

Otherwise, if

$$
\left|u_{n}^{\prime}\right|>u_{n}>\tau \text { for } t \in[0,1]
$$

it follows from (4.21) that

$$
f\left(t, u_{n}, u_{n}^{\prime}\right) \leq \varphi_{p}\left(\frac{u_{n}}{W}\right) \leq \varphi_{p}\left(\frac{c_{n}^{*}}{W}\right) \text { for } t \in[0,1]
$$

which contradicts (4.19).

Let

$$
W=\max _{\left(t, u, u^{\prime}\right) \in[0,1] \times[0, \tau] \times[-\tau, \tau]} f\left(t, u, u^{\prime}\right),
$$

then

$$
f\left(t, u_{n}, u_{n}^{\prime}\right) \leq W(n=1,2, \ldots)
$$

which also contradicts (4.20). 
Theorem 4.3. Suppose that there exist constants $a_{i}^{*}, b_{i}^{*}$, and $d_{i}^{*}$ such that

$$
0<a_{1}^{*}<b_{1}^{*}<\frac{N}{W} d_{2}^{*}<a_{2}^{*}<b_{2}^{*}<\frac{N}{W} d_{3}^{*}<\cdots<a_{n}^{*}<b_{n}^{*}<\frac{N}{W} d_{n+1}^{*},
$$

here, $n \in \mathbb{N}$ and $i=1,2, \ldots, n$. In addition, suppose that $f$ satisfies the following conditions:

(i) $f\left(t, u, u^{\prime}\right) \leq \varphi_{p}\left(d_{i}^{*} / W\right)$ for $\left(t, u, u^{\prime}\right) \in[0,1] \times\left[0, d_{i}^{*}\right] \times\left[-d_{i}^{*}, d_{i}^{*}\right]$,

(ii) $f\left(t, u, u^{\prime}\right)>\varphi_{p}\left(b_{i}^{*} / N\right)$ for $\left(t, u, u^{\prime}\right) \in\left[\eta, \omega_{1}\right] \times\left[b_{i}^{*}, d_{i}^{*}\right] \times\left[-d_{i}^{*}, d_{i}^{*}\right]$,

(iii) $f\left(t, u, u^{\prime}\right)<\varphi_{p}\left(a_{i}^{*} / M\right)$ for $\left(t, u, u^{\prime}\right) \in\left[0, \omega_{1}\right] \times\left[0, a_{i}^{*}\right] \times\left[-d_{i}^{*}, d_{i}^{*}\right]$.

Then, problem (1.2) has at least $2 n-1$ positive pseudosymmetric solutions.

Proof. When $n=1$, it is immediate from condition (i) that

$$
A: \bar{P}_{a_{1}^{*}} \longrightarrow P_{a_{1}^{*}} \subset \bar{P}_{a_{1}^{*}}
$$

It follows from the Schauder fixed point theorem that $A$ has at least one fixed point

$$
u_{1} \in \bar{P}_{a_{1}^{*}}
$$

which means that

$$
\left\|u_{1}\right\| \leq a_{1}^{*}
$$

When $n=2$, it is clear that Theorem 4.1 holds (with $a^{*}=a_{1}^{*}, b^{*}=b_{1}^{*}$, and $d^{*}=d_{2}^{*}$ ). Then, there exists at least three positive pseudosymmetric solutions $u_{1}, u_{2}$, and $u_{3}$ such that

$$
\begin{gathered}
\left\|x_{1}\right\| \leq d_{2}^{*}, \quad\left\|x_{2}\right\| \leq d_{2}^{*}, \quad\left\|x_{3}\right\| \leq d_{2}^{*}, \quad b^{*}<\min _{t \in\left[\eta, \omega_{1}\right]} u_{1}(t), \quad a_{1}^{*}<\max _{t \in[0,1]} u_{2}(t), \\
\min _{t \in\left[\eta, \omega_{1}\right]} u_{2}(t)<b_{1}^{*} \text { with } \max _{t \in[0,1]} u_{3}(t)<a_{1}^{*} .
\end{gathered}
$$

Following this way, we finish the proof by induction. The proof is complete.

\section{Examples}

In this section, we present two simple examples to illustrate our results.

Example 5.1. Consider the following BVPs:

$$
\begin{gathered}
\left(\varphi_{p}\left(u^{\prime}(t)\right)\right)^{\prime}+t\left(t+1+\left|u^{\prime}(t)\right|^{p-2}\right)=0, \quad t \in[0,1], \\
u(0)=0, u(0.2)=u(1) .
\end{gathered}
$$


Note that

$$
\begin{gathered}
f_{0}=\inf _{t \in[0,1]\left(u, u^{\prime}\right) \rightarrow(0,0)} \lim _{t+1+\left|u^{\prime}(t)\right|^{p-2}}=\infty, \\
f^{\infty}=\sup _{t \in[0,1]} \lim _{\left(u, u^{\prime}\right) \rightarrow(\infty, \infty)} \frac{t+1+\left|u^{\prime}(t)\right|^{p-2}}{\left|u^{\prime}(t)\right|^{p-2} u^{\prime}(t)}=0 .
\end{gathered}
$$

Hence, Theorem 3.2 implies that the BVPs in (5.1) have at least one pseudosymmetric solution $u$.

Example 5.2. Consider the following BVPs with $p=3$ :

$$
\begin{gathered}
\left(\varphi_{p}\left(u^{\prime}(t)\right)\right)^{\prime}+h(t) f\left(t, u(t), u^{\prime}(t)\right)=0, t \in[0,1], \\
u(0)=0, u(0.2)=u(1),
\end{gathered}
$$

where $h(t)=2 t$ and

$$
f\left(t, u, u^{\prime}\right)= \begin{cases}t+4+\left(\frac{u^{\prime}}{5.5}\right)^{2}, & u \in[0,0.9], \\ t+750 u-671+\left(\frac{u^{\prime}}{5.5}\right)^{2}, & u \in[0.9,1], \\ t+79+\left(\frac{u^{\prime}}{5.5}\right)^{2}, & u \in[1,5.5], \\ t+14.364 u+\left(\frac{u^{\prime}}{5.5}\right)^{2}, & u \in[5.5,+\infty) .\end{cases}
$$

Note that $\eta=0.2, \omega_{1}=0.6$, then a direct calculation shows that

$$
M=\omega_{1} \varphi_{q}\left(\int_{0}^{\omega_{1}} h(r) d r\right)=0.6 \times 0.6=0.36, N \approx 0.1131, W=0.6
$$

If we take $a^{\prime}=0.9, b^{\prime}=1, d^{\prime}=5.5$, then $a^{\prime}<b^{\prime}<(N / W) d^{\prime}$ holds; furthermore,

$$
\begin{aligned}
& f\left(t, u, u^{\prime}\right)<82<84.028 \approx \varphi_{p}\left(\frac{d^{\prime}}{W}\right) \quad \text { for }\left(t, u, u^{\prime}\right) \in[0,0.6] \times[0,5.5] \times[-5.5,5.5], \\
& f\left(t, u, u^{\prime}\right)>79>78.176 \approx \varphi_{p}\left(\frac{b^{\prime}}{N}\right) \text { for }\left(t, u, u^{\prime}\right) \in[0.6,1] \times[1,5.5] \times[-5.5,5.5], \\
& f\left(t, u, u^{\prime}\right)<6.2<6.25=\varphi_{p}\left(\frac{a^{\prime}}{M}\right) \quad \text { for }\left(t, u, u^{\prime}\right) \in[0,0.6] \times[0,0.9] \times[-5.5,5.5] .
\end{aligned}
$$


By Theorem 4.1, we see that the BVPs in (5.3) have at least three positive pseudosymmetric solutions $u_{1}, u_{2}$ and $u_{3}$ such that

$$
\begin{gathered}
\left\|x_{i}\right\| \leq 5.5 \text { for } i=1,2,3,1<\min _{t \in[0.2,0.6]} u_{1}(t), 0.9<\max _{t \in[0,1]} u_{2}(t), \\
\min _{t \in[0.2,0.6]} u_{2}(t)<1 \quad \text { with } \max _{t \in[0,1]} u_{3}(t)<0.9 .
\end{gathered}
$$

\section{Acknowledgments}

Y. H. Su Sponsored by Qing Lan Project and XZIT (no. XKY2010101). X. Yan Supported by Fundamental Research Funds for the Central Universities Grant (no. 2010QNA40).

\section{References}

[1] C. Bai, "Triple positive solutions of three-point boundary value problems for fourth-order differential equations," Computers \& Mathematics with Applications, vol. 56, no. 5, pp. 1364-1371, 2008.

[2] R. Ma and H. Ma, "Positive solutions for nonlinear discrete periodic boundary value problems," Computers \& Mathematics with Applications, vol. 59, no. 1, pp. 136-141, 2010.

[3] R. Ma and B. Zhu, "Existence of positive solutions for a semipositone boundary value problem on the half-line," Computers E Mathematics with Applications, vol. 58, no. 8, pp. 1672-1686, 2009.

[4] J.-P. Sun and Y.-H. Zhao, "Multiplicity of positive solutions of a class of nonlinear fractional differential equations," Computers $\mathcal{E}$ Mathematics with Applications, vol. 49, no. 1, pp. 73-80, 2005.

[5] D.-B. Wang and W. Guan, "Three positive solutions of boundary value problems for $p$-Laplacian difference equations," Computers $\mathcal{E}$ Mathematics with Applications, vol. 55, no. 9, pp. 1943-1949, 2008.

[6] Y. Zhu and J. Zhu, "Existence of multiple positive solutions for $n$ th-order $p$-Laplacian $m$-point singular boundary value problems," Journal of Applied Mathematics and Computing, vol. 34, no. 1-2, pp. 393-405, 2010.

[7] R. Avery and J. Henderson, "Existence of three positive pseudo-symmetric solutions for a one dimensional discrete $p$-Laplacian," Journal of Difference Equations and Applications, vol. 10, no. 6, pp. 529-539, 2004.

[8] R. I. Avery and J. Henderson, "Existence of three positive pseudo-symmetric solutions for a onedimensional p-Laplacian," Journal of Mathematical Analysis and Applications, vol. 277, no. 2, pp. 395 404, 2003.

[9] M. Feng, X. Zhang, and W. Ge, "Exact number of pseudo-symmetric positive solutions for a $p$ Laplacian three-point boundary value problems and their applications," Applied Mathematics and Computing, vol. 33, no. 1-2, pp. 437-448, 2010.

[10] D. Ji, Y. Yang, and W. Ge, "Triple positive pseudo-symmetric solutions to a four-point boundary value problem with p-Laplacian," Applied Mathematics Letters, vol. 21, no. 3, pp. 268-274, 2008.

[11] D.-X. Ma and W.-G. Ge, "Existence and iteration of positive pseudo-symmetric solutions for a threepoint second-order $p$-Laplacian BVP," Applied Mathematics Letters, vol. 20, no. 12, pp. 1244-1249, 2007.

[12] J. T. Cho and J.-I. Inoguchi, "Pseudo-symmetric contact 3-manifolds. II. When is the tangent sphere bundle over a surface pseudo-symmetric?" Note di Matematica, vol. 27, no. 1, pp. 119-129, 2007.

[13] S. W. Ng and A. D. Rae, "The pseudo symmetric structure of bis(dicyclohexylammonium) bis(oxalatotriphenylstannate)," Zeitschrift für Kristallographie, vol. 215, no. 3, pp. 199-204, 2000.

[14] T. Jankowski, "Existence of positive solutions to second order four-point impulsive differential problems with deviating arguments," Computers $\mathcal{E}$ Mathematics with Applications, vol. 58, no. 4, pp. 805-817, 2009.

[15] X.-F. Li and P.-H. Zhao, "The existence of triple positive solutions of nonlinear four-point boundary value problem with $p$-Laplacian," Turkish Journal of Mathematics, vol. 33, no. 2, pp. 131-142, 2009.

[16] B. Sun and W. Ge, "Successive iteration and positive pseudo-symmetric solutions for a three-point second-order $p$-Laplacian boundary value problems," Applied Mathematics and Computation, vol. 188, no. 2, pp. 1772-1779, 2007. 
[17] Y. Wang and W. Gao, "Existence of triple positive solutions for multi-point boundary value problems with a one dimensional $p$-Laplacian," Computers $\mathcal{E}$ Mathematics with Applications, vol. 54, no. 6, pp. 793-807, 2007.

[18] F. Xu, L. Liu, and Y. Wu, "Multiple positive solutions of four-point nonlinear boundary value problems for a higher-order $p$-Laplacian operator with all derivatives," Nonlinear Analysis: Theory, Methods E Applications, vol. 71, no. 9, pp. 4309-4319, 2009.

[19] R. I. Avery, "A generalization of the Leggett-Williams fixed point theorem," Mathematical Sciences Research Hot-Line, vol. 3, no. 7, pp. 9-14, 1999.

[20] M. A. Krasnosel'skii, Positive Solutions of Operator Equations, P. Noordhoff, Groningen, The Netherlands, 1964.

[21] R. I. Avery and A. C. Peterson, "Three positive fixed points of nonlinear operators on ordered banach spaces," Computers \& Mathematics with Applications, vol. 42, no. 3-5, pp. 313-322, 2001.

[22] D. J. Guo and V. Lakshmikantham, Nonlinear Problems in Abstract Cones, vol. 5 of Notes and Reports in Mathematics in Science and Engineering, Academic Press, San Diego, Calif, USA, 1988.

[23] H. Wang, "Positive periodic solutions of functional differential equations," Journal of Differential Equations, vol. 202, no. 2, pp. 354-366, 2004. 


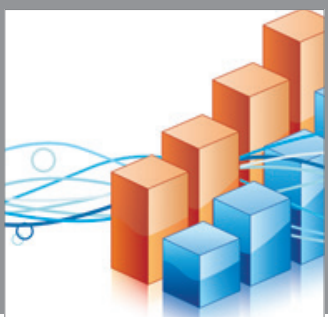

Advances in

Operations Research

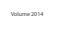

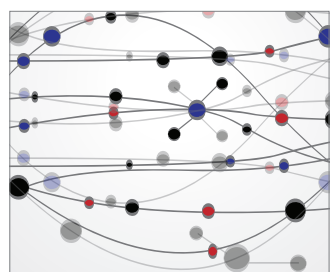

\section{The Scientific} World Journal
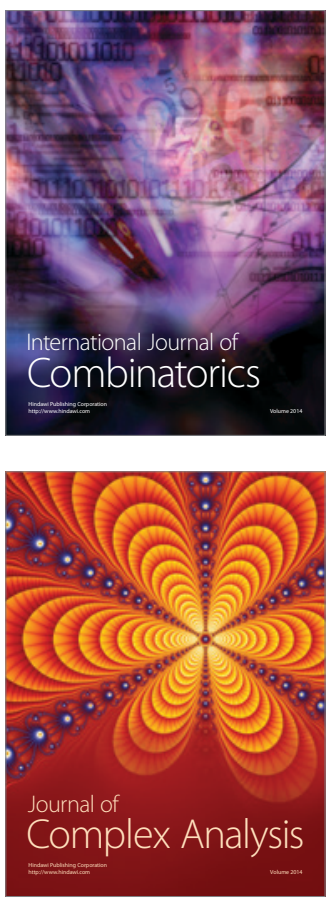

International Journal of

Mathematics and

Mathematical

Sciences
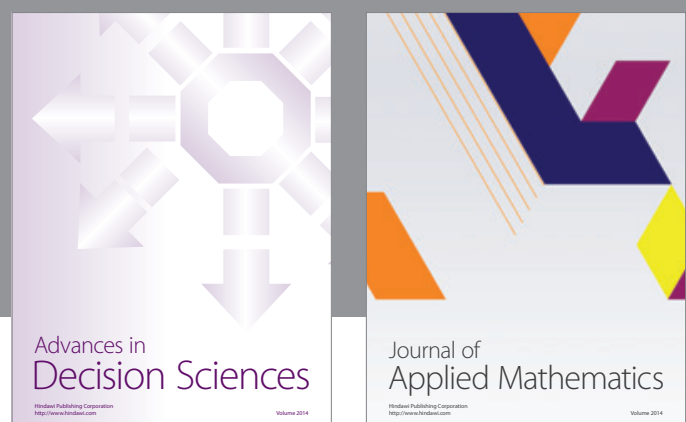

Journal of

Applied Mathematics
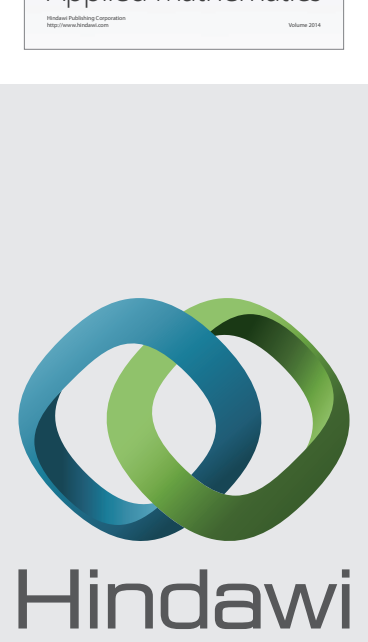

Submit your manuscripts at http://www.hindawi.com
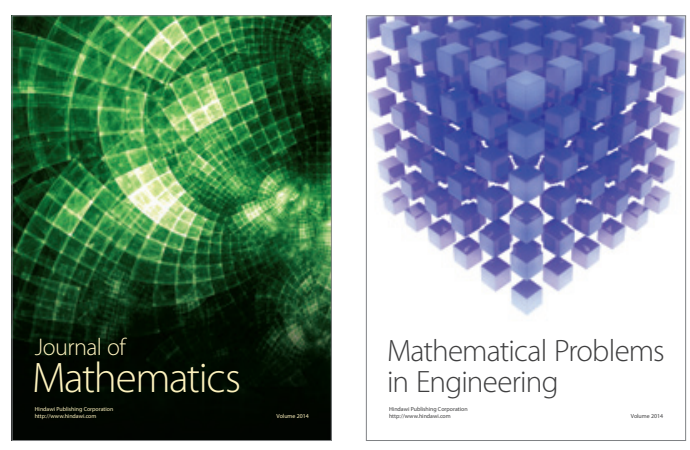

Mathematical Problems in Engineering
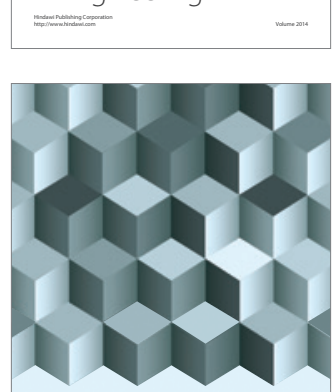

Journal of

Function Spaces
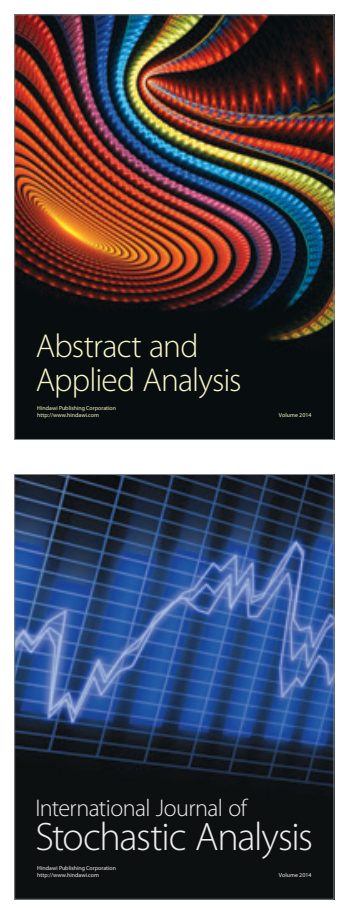

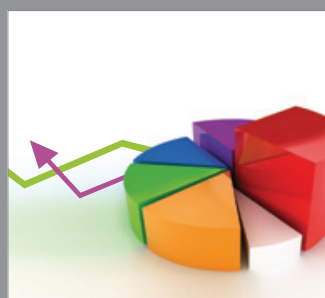

ournal of

Probability and Statistics

Promensencen
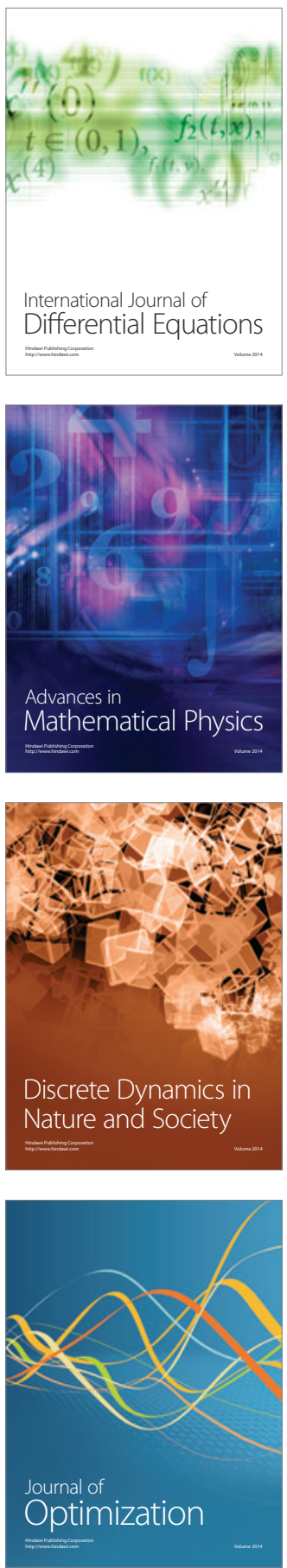